\title{
NUTRITIONAL STATUS OF BASIDIOMYCETOUS FUNGI ASSOCIATED WITH CASUARINA FROM TAMILNADU
}

\author{
${ }^{1}$ Kulkarni Sangita* and ${ }^{2}$ Kulkarni Abhijit \\ ${ }^{1}$ Radhabai Kale Mahila Mahavidyalaya, Ahmednagar \\ ${ }^{2}$ Department of Botany, Ahmednagar College, Ahmednagar \\ *Corresponding Author: sangitakulkarni69@gmail.com
}

\begin{abstract}
:
Present study dealt with study of nutritional status of Basidiomycetous fungi associated with Casuarina. During the investigation various carbon and nitrogen sources were used and the basidiomycetous fungi such as Podaxis pistillaris and Clavaria species were grown invitro. It was found that Podaxis pistillaris flourishes best with xylose and Raffinose sugars as carbon sources and sodium nitrate and sodium ammonium nitrate as nitrogen sources. Clavaria sp. grows best with the carbon sources like mannitol and maltose. Glutamine and sodium ammonium nitrate as nitrogen sources for the growth of Clavaria. The inorganic sources help in faster growth of fungus. The effect of growth is positive when the sources are used in combinations.
\end{abstract}

Key words: - Podaxis pistillaris, Clavaria

\section{INTRODUCTION:}

Casuarina, a member of the family Casuarinaceae, is a native of Australia. They are successfully introduced in the east coast of Indian Peninsula in 1960s and then cultivated in all parts of the country. Species of Casuarina is planted on a large scale in different parts of our country where there is longer dry season and less water contents. Casuarinas are salt tolerant and adaptable to poor soils with least requirements for their growth. In South India they are grown on coastal areas with sandy soils as well as in interiors with loam soils. The Casuarina plantations are abundant along the seashores of Tamilnadu. The plant is a multipurpose tree in Agro-forestry. The tree gives diffused shade, improves physical and chemical properties of soil, suppresses the weeds, helps in maintaining the fertility of soil, used as food, fuel and fodder and acts as good wind breaker.

Fungi utilize dead plant tissues and the soluble substrates including root exudates and develop themselves in rhizoplane and rhizosphere. Members of Ascomycetes and Basidiomycetes are reported to be present in rhizosphere. Casuarina plants from different localities were surveyed for Basidiomycetous fungi and their ectomycorrhizal association. During the study, Podaxix pistilaris, Clavaria sp., Lycoperdon sp., Calvatia sp. and some mushrooms were found associated with Casuarina plantations. These forms did not have any Ectomycorrhizal association with the plants.

Present investigation dealt with studies on Basidiomycetous fungi occurring in the rhizosphere of Casuarina from Tamilnadu and their nutritional requirements.

MATERIAL AND METHODS:

In the present study the material of basidiomycetous fungi Podaxix pistilaris, Clavaria species associated with Casuarina was collected from sites of Chennai, Mahabalipuram and Trichur (Tamilnadu 
state). The species of podaxis and Clavaria were selected for nutritional studies. The work was undertaken in following steps:

1. Two fungi Podaxis and Clavaria were selected for study. The fungal spores were collected and grown in axenic cultures on Malt agar plates incubated at $27^{\circ} \mathrm{C}$ for 48 hours.

2. After the growth of hyphae, the hyphal mat was punched with the help of corn borer and used as a source of inoculum.

3. The inoculums was added to the agar plates with different nitrogen and carbon sources were inoculated at $27^{\circ} \mathrm{C}$ for 48 hours till 144 hours in diffused light conditions and recorded in tables ( Table - I \& II).

4. The different nitrogen sources included Cysteine, Alanine, Glutamine, Sodium nitrate, Threonine, Ammonium oxalate, Sodium nitrate and Sodium ammonium nitrate which were added in the concentrations of $0.05 \%$ in the basal medium (Modified Pridham \& Gottlieb medium ;1948).

5. Different carbon sources included were Sorbitol, Lactose, Xylose, Mannitol, Galactose, Maltose and Raffinose which were added in the concentrations of $3.5 \%$ in the basal medium.

\section{OBSERVATIONS AND RESULTS:}

Based on the nutritional requirements it is concluded that

1. Podaxis pistillaris flourishes best with xylose and Raffinose sugars as carbon sources and sodium nitrate and sodium ammonium nitrate as nitrogen sources.

2. Clavaria sp. grows best with the carbon sources like mannitol and maltose as well as Glutamine and sodium ammonium nitrate as nitrogen sources.

3. The inorganic sources help in faster growth of fungus.

4. The effect of growth is positive when the sources are used in combinations.

5. Structurally the fungi belonged to gastromycetes group and the nutritional analysis indicated the use of inorganic nitrogen sources and disaccharides as carbon sources either single or in combination has helped in better growth of fungi.

6. The Casuarina plant litter and residue provides the inorganic sources of carbon and nitrogen for the growth of the fungi around them.

\section{REFERENCES:}

Abhijit Kulkarni 1995. Thesis: Mycroflora associated with the roots of Casuarina.

Brown G.D. 1984. Trees roots and the use of soil nutrients. In: Nutrition of plantation Forests (eds. G.D. Brown and S.K.S. Nambair) Academic press, London, pp. 147-167.

Costas Theodorou and Paul Reddell. 1991. In vitro synthesis of ectomycorrhizas on Casuarinaceae with a range of mycorrhizal fungi. New Phytologist: Pp. 279-288.

Garrett S.D. 1955. Microbial ecology of the soil. Trans. Brit. Mycol. Soc. 38 (1): 1-7.

Nair L. N and V.P.Kaul 1984. Nutritional studies on Pleurotus I nitrogen and carbon J. Univ. Pune. Sci. Tech. 56: 99-104.

Nair L.N. and Veena Ganju 1989. Nutritional studies on Pleurotus II - Growth regulators. Vegetos 2 (2) : 206-211. 
TABLE: I

A. Carbon nutrition studies - Podaxis

\begin{tabular}{|c|c|c|c|c|c|c|c|}
\hline \multicolumn{7}{|c|}{ Diameter of colony in cms } \\
\hline Hours & Sorbitol & Lactose & Xylose & Mannitol & Galactose & Maltose & Raffinose \\
\hline 48 & 1.0 & 1.8 & 2.7 & 1.0 & 2.0 & 2.8 & 2.4 \\
\hline 72 & 1.9 & 3.0 & 3.5 & 3.0 & 2.1 & 3.2 & 3.4 \\
\hline 96 & 1.9 & 3.0 & 4.5 & 4.0 & 2.8 & 3.9 & 4.0 \\
\hline 120 & 2.0 & 3.9 & 5.8 & 5.5 & 3.0 & 3.9 & 5.0 \\
\hline 144 & 2.3 & 4.1 & 6.5 & 5.5 & 3.8 & 4.1 & 5.9 \\
\hline Mean & $1.8 \pm 0.9$ & $3.1 \pm 0.1$ & $\mathbf{4 . 6 \pm 0 . 9}$ & $3.8 \pm 0.2$ & $2.7 \pm 0.9$ & $3.5 \pm 0.2$ & $\mathbf{4 . 1} \pm \mathbf{0 . 1}$ \\
\hline $\begin{array}{l}\text { Type of } \\
\text { growth }\end{array}$ & Scanty & Scanty & Normal & Moderate & Scanty & Scanty & Normal \\
\hline
\end{tabular}

B. Carbon nutrition studies - Clavaria

\begin{tabular}{|c|c|c|c|c|c|c|c|}
\hline \multicolumn{7}{|c|}{ Diameter of colony in cms } \\
\hline Hours & Sorbitol & Lactose & Xylose & Mannitol & Galactose & Maltose & Raffinose \\
\hline 48 & 2.0 & 3.4 & 2.5 & 2.5 & 2.0 & 4.4 & 1.9 \\
\hline 72 & 2.7 & 4.4 & 4.2 & 4.6 & 3.6 & 5.7 & 3.5 \\
\hline 96 & 3.0 & 5.6 & 5.3 & 7.5 & 5.2 & 7.5 & 3.5 \\
\hline 120 & 3.4 & 6.3 & 5.7 & 8.4 & 7.0 & 8.8 & 3.7 \\
\hline 144 & 4.0 & 6.8 & 6.0 & 9.3 & 7.2 & 10.0 & 4.0 \\
\hline Mean & $3.0 \pm 0.4$ & $5.3 \pm 0.8$ & $4.7 \pm 0.9$ & $\mathbf{6 . 4} \pm \mathbf{0 . 1}$ & $5.0 \pm 0.3$ & $\mathbf{7 . 2} \pm \mathbf{0 . 1}$ & $3.3 \pm 0.1$ \\
\hline $\begin{array}{c}\text { Type of } \\
\text { growth }\end{array}$ & Scanty & Scanty & Scanty & Normal & Scanty & Normal & Scanty \\
\hline
\end{tabular}

TABLE: II

A. Nitrogen nutrition studies - Podaxis

\begin{tabular}{|c|c|c|c|c|c|c|c|}
\hline \multicolumn{7}{|c|}{ Diameter of colony in cms } \\
\hline Hours & Cystiene & Alanine & Glutamine & Threonine & $\begin{array}{c}\text { Amm. } \\
\text { oxalate }\end{array}$ & $\begin{array}{c}\text { Na } \\
\text { nitrate }\end{array}$ & $\begin{array}{c}\mathrm{NaNH}_{4} \\
\text { nitrate }\end{array}$ \\
\hline 48 & 1.2 & 1.5 & 1.5 & 1.4 & 1.5 & 1.5 & 1.5 \\
\hline 72 & 1.7 & 2.1 & 2.1 & 2.0 & 2.0 & 2.4 & 2.4 \\
\hline 96 & 2.5 & 2.7 & 2.7 & 2.6 & 2.4 & 3.0 & 3.0 \\
\hline 120 & 3.1 & 3.4 & 3.0 & 3.0 & 3.1 & 3.6 & 3.6 \\
\hline 144 & 3.3 & 3.6 & 3.1 & 3.0 & 3.3 & 4.1 & 4.1 \\
\hline Mean & $2.3 \pm 0.9$ & $2.6 \pm 0.1$ & $2.4 \pm 0.1$ & $2.4 \pm 0.1$ & $2.4 \pm 0.1$ & $\mathbf{2 . 9} \pm \mathbf{0 . 2}$ & $\mathbf{2 . 9} \pm \mathbf{0 . 2}$ \\
\hline $\begin{array}{c}\text { Type of } \\
\text { growth }\end{array}$ & Scanty & Scanty & Scanty & Scanty & Scanty & Normal & Normal \\
\hline
\end{tabular}


B. Nitrogen nutrition studies - Clavaria

\begin{tabular}{|c|c|c|c|c|c|c|c|}
\hline \multicolumn{9}{|c|}{ Diameter of colony in cms } \\
\hline Hours & Cystiene & Alanine & Glutamine & Threonine & $\begin{array}{c}\text { Amm. } \\
\text { Oxalate }\end{array}$ & $\begin{array}{c}\text { Na } \\
\text { nitrate }\end{array}$ & $\begin{array}{c}\mathrm{NaNH}_{4} \\
\text { nitrate }\end{array}$ \\
\hline 48 & 0.7 & 3.2 & 4.2 & 4.9 & 4.5 & 1.9 & 3.5 \\
\hline 72 & 0.7 & 5.4 & 6.0 & 6.4 & 6.0 & 4.4 & 5.8 \\
\hline 96 & 0.7 & 6.4 & 7.4 & 7.0 & 7.0 & 6.0 & 7.2 \\
\hline 120 & 0.7 & 7.5 & 8.5 & 8.0 & 7.5 & 6.7 & 9.0 \\
\hline 144 & 0.8 & 8.5 & 9.0 & 8.5 & 8.0 & 7.9 & 9.5 \\
\hline Mean & $0.7 \pm 0.2$ & $6.2 \pm 0.1$ & $\mathbf{7 . 0 \pm 0 . 2}$ & $6.9 \pm 0.8$ & $6.8 \pm 0.2$ & $5.3 \pm 0.2$ & $\mathbf{7 . 0 \pm 0 . 2}$ \\
\hline $\begin{array}{l}\text { Type of } \\
\text { growth }\end{array}$ & Scanty & Moderate & Normal & Moderate & Moderate & Scanty & Normal \\
\hline
\end{tabular}
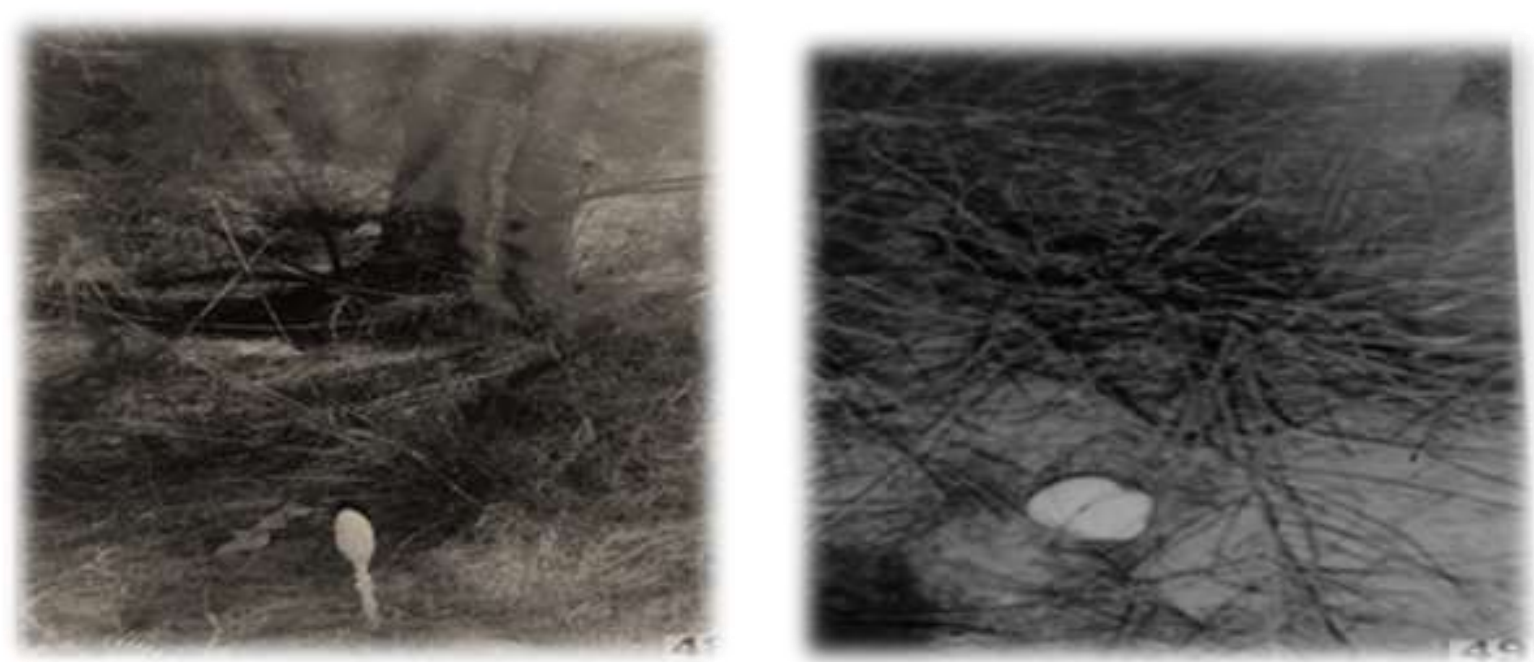

Podaxis pistillaris

\section{Clavaria sp.}

